\title{
GEOSPATIAL INFORMATION SYSTEM FOR TOURISM MANAGEMENT IN AURANGABAD CITY- A REVIEW
}

\author{
Pallavi U.Pandagale ${ }^{1}$, Manisha R.Mundhe ${ }^{2}$, Amin Pathan ${ }^{3}$ \\ ${ }^{I}$ Dept. of CS and IT, Dr.B.A.M. University, Aurangabad \\ ${ }^{2}$ Dept. of CS and IT, Dr.B.A.M. University, Aurangabad \\ ${ }^{3}$ Dept. of CS and IT, Dr.B.A.M. University, Aurangabad
}

\begin{abstract}
Aurangabad is a historic city located in the heart of Maharashtra. It is rapidly becoming a hot spot for tourist from around the world because of its exotic locations and facilities provide by the government. This paper describes the development of the tourism management and planning by the integration with the Geographic information system (GIS). The tool of the tourist industry is more and more emerging as the internet. It is a present the perfect platform that brings to the product and service to the client. However world-wide web is fast becoming useful tool for the tourism industry and it presents a platform that brings products and services to the user. In generally tourist wants to find objects of tourism and amenities with reference to their geographic position and surroundings. In most case, it is not satisfying to find a tourist place without a reference to historical place sight or event location located nearby. In the present work, an effort has been gained to build up a tourism management model using the Google earth/Google Map and KML file techniques. The study presents a paper start from the client needs to present the tourist object in geospatial context on the interactive map supports planning the tourism and focusing on the analysis decision making and management using Google earth or Google map and KML file technique and finally presenting the result on the internet.
\end{abstract}

Keywords-Geographic information systems (GIS), Web based tourism application, Open Geospatial Consortium (OGC), KML.

\section{INTRODUCTION}

The world's largest and fastest growing sector of the global economy in the tourism industry. It is defined as composite of facilities, activities, services and industries that deliver a travel experience that is accommodation, eating and drinking establishments, transportation, entertainment, historical and cultural experiences, destination attractions, recreation, shopping and other services available to travel away from home. The coastal lines on the touristic activities accelerated and the number of people participating that has been reached to more or more than 600 million a year. A maximum benefits or the zones coastal according to the basic of sustainable development possible using the management plans suitable the characteristics of the area and it is very common, becoming effective fast decision making using the possible GIS. Many companies are the software and support to the specific industry. The tourist industry using the GIS application are the analysis of current and potential client, analysis line of site for the new attraction such as bus routes, railway routes etc. The GIS technologies are implemented in the tourism industry being that are future holds in the tip of the iceberg.

\section{CURRENT USE OF GIS INTOURISM}

\section{INDUSTRY}

The use of GIS system is therefore classified into two categories according to the client vis. Management user and public user. Public user is the tourists using the maps for navigating towards their destination. They are interested in tourism geographic or location specific information about a place or a region. Further, the tourist may be interested to know about the available amenities, facilities and also the climate of the region or place where they intend to visit.

The management users consist of individual employers such as tour operators, tourism group, policy makers or a local municipal administration for tourism. Specific strategic planning or decision making. Management user is more interested to know the location of their socio-economic background and potential location for new tourist sites in the region.

\subsection{Study Area- Aurangabadcity}

Aurangabad city is a historic city in located in the heart of Maharashtra. A tourist hub surrounded with many famous historical and culture monuments and natural resorts including the Ajanta and the Ellora Caves, Bibikamaqbara and panchakki and development of the tourism information with its modern tourist facilities, destinations, and activities. It is rapidly becoming a hot spot for tourist from around the world because of its exotic locations and facilities provide by the government. The city is located between $19^{\circ} 53^{\prime} 0^{\prime \prime} \mathrm{N}$ Latitude and $75^{\circ} 20^{\prime} 00^{\prime \prime} \mathrm{E}$ Longitude and the total geographical area of the is 135.75 sq.k.m .The city of 54 Gates but only 13 have survived over period of time and the 
presence of these can be felt as going on one drive in the city. In currently there are 35 tourist attractions/ locations in city and today city has annual inflow of 25 lakh tourists every year and which is still increasing. The Tourism potential of the district is not fully tapped due to international gaps, connectivity, Services Quality, inadequate basics amenities and marketing promotion. But there are various issues faced by the Aurangabad tourism for the development of tourism some of them are lack of proper infrastructure, Access and Connectivity, Amenities, Service level. The application providing information of places and enabling the provision of new smart services. Geographical Information which allows users to view places as if standing upon them. Tour with a Themed Information, which highlights tourist attractions, providing its users a virtual tour of Aurangabad city. The help of the GIS application the tourist will be able to know the information about the place near city and explore about the tourist place all necessary information. Because of the development of the GIS based tourist information the visitors will be mange and plan their trips and complete their journey with more comfort and ease from the start to end and that can be determined easily and systematically using by the study area and exposed with the GIS but also proved that can be applied to these studies. The GIS can be acts as potential techniques in planning, managing and marketing the tourism products. Presently the tourism is being promoted and marketed to the world through the Internet and Web as one of the mediums of advertising. But still it is needs to be projected in a better way to the customer with the utmost possible information to increase itsmarketability. Geospatial data can be used to enhance the tourist web site of a region whichwill give a new look with added functions to browse the information in a more innovate, interesting and better way, so that the prospective tourist researcher turns into a tourist for the region.

\subsection{GIS Web Based Application}

We people have more access to tourism information than ever before worldwide web. Internet provides a way to publish the tourist information over the web which can be accessed anywhere in the word through proper means technology gained popularity among the public or users as it was more convenient ,time saving and independent to use without depending on any individual like travel operators etc. The determining whether the accessing information on the internet has become is less question. The Geographic information used organization has changed the way in the internet the use of GIS. The processes of accessing, analyzing data and sharing disseminating. The GIS online combines with the advantages in internet program more than becomes visual and analytical tool the users help to visualize or understand information in a map. The enable users to manage with the interactively and analytically information. Therefore a web based GIS that can be built as tourism in decision making. With the tourism information system that has been using developed in the web technologies.

\section{DATA COLLECTION}

The technologies within the language of open geospatial consortium (OGC) standards in-order to more fully understand urban systems.[1] Working with the KML and Google API for locating the available \& analyzing their properties for tourist information system in the Aurangabad city. Designing and developing a website that provides both spatial and non spatial tourism information using Google earth/Google map KML language. In the first step collect all tourist sport, historical sport, historical and cultural socioeconomic data, facilities concerning to the study are form a database. Second data that are regarding to the study area and these data related with the database formed in the tourism information system that provide details about these tourist locations like their address and operating time and various other details. Those support public access of data to get calculative information while giving efficient way to organization to represent them. Third obtain of the historical and cultural in the city tourist place and hotel to connect with the graphical data in the tourism information system. Fourth they prepare a software an which is developed to the tourist query and tourist which is uses tourism information system the fastest and easiest by icons and sign. Fifth this step of the study is use required software to transform tourism information system. Which it is a formed with all visual, literary, and graphical data into a system can be supply a query on internet. This is challenging objective, all the complex information generated is to be managed geographically. Managing geographically and representing organization, places give user an efficient way to get structure easily.

\subsection{Geographic Query}

The technologies of multiple integration including the tourism information system Geographic information system and internet that has been given to an existing new access to the tourism information system. An tourism information based the tourist value system, society and service inform that about the location of the touristic objects like tourist and historical place, hotel, restaurants ,museums, bus stand, railway station etc. and the tourist helps to finding the most relevant accommodation and or locate the position of a specific tourist place. The tourism information system existing do not reflect this requirement. It is possible to search for tourist place in a city. The sufficient might be small cities but of course will not be deliver satisfying results for the bigger cities and more detailed location specification that is needed. The tourism information system of a geographic tourist quickly search to the database using the geographic criteria it is a mixed query an which is the combines with the tourism attributes and geographic criteria .Here, What represents attributes of touristic object and where the geographic space that the touristic place covered? The operations some are spatial analysis are needed to that provide for easy search operation to a tourist. Nearness, distance and region these operation are geographic criterions. The nearness defined as to search for the nearest touristic object to givens marks. The distance defined as to search for the find elements located within 
specified distance to givens marks. The region defined as to search for the object located within a region marked on the map. It is search can be category into different search types. For Example:-Location of specific object shows where the "BibikaMaqbara" is located show the location of the "Panchakki" tourist place. And Nearest object to a specific object are which the nearest hotel to "taj" is? Which sight has the smallest distance to the "lemon tree" hotel? And where is the nearest bus station to the bibi ka maqbara" place.

\section{LITERATURE SURVEY}

The advancement in modern technology many opportunities for the application of Geographic information system (GIS) in tourism are available for the development of the tourism sector. The fusion of remote sensing with the Geographical Information System (GIS) technologies has been vastly implemented and recognized effectively in the urban analysis and modeling. According application of SPOT data for regional growth analysis and local planning and GIS is recognized widely and accepted as a valuable tool for analyzing, managing, and displaying large volumes of diverse data pertinent to many local and regional planning activities. Its use intourism planning and management becomes imperative. (Ethlers, M.; Jadkowski, M.A.; Howard, R.R.; Brostuen 1990, 56,175-180).[2]. A study on the value and scope of geographical information system in tourism management the main objective were to overcome the short-term management strategies or an ignorance of more sustainable form of tourism. Most importantly it is necessary to clearly understand the nature, scope and impact of the TDA when evaluating the relevance and benefits of a GIS. [3].

The recent technology developments based on Geographic Information System (GIS) and satellite images have provided a new way of accessing location-based information. It can provide with the interactive mapping services as well as realistic satellite images and more importantly the free application programming interface (API) allows thousands of programmers to tap into the powerful Google mapping service by connecting it with various types of data Combined with destination-specific tourist information. It could provide a new way of trip planning and tourist information accessing. [4].This study on the Tourist Information System for tourism development in the Pune district. The main objective was to collect the information about tourism facilities available at that time and to find out the potential tourist sites and their suitability in the area with the help of GIS technique. [5].

The research on the geographical investigation of tourism in Raigad district. It was observed that the conditions of state highway, district roads and village roads were not at all satisfactory which was one of the main drawback in the development of the region as a tourist centre, as it was a mandatory to develop the various government authorities such as PWD, MTDC and local leaders were intimated and were said to take the matter into consideration and take lead and were to develop the roads and routes for the transportation were to be improved. [6]Rajasthan Development Tourism consisting of various statistical tools such as standard, mean deviation, coefficient of variance and $t$ test were employed. A detailed view on the data was made, classified and analyzed using all type of relevant techniques implement the most appropriate tests. As per the government, all the private entrepreneurs should contribute to this sector, due to which it will help to increase and raise the revenue, to develop and serve the tourists with the best services and for the further enhancement of the tourism sector. [7].The developing on the thematic maps online with the help of php, $\mathrm{kml}$ and Google earth api for visualizing the indicators selected for the slovak republic. The key was to evaluate the existing Web applications was to the demonstrate and a general possibilities of using PHP scripting language and KML format in the field of Thematic Mapping. And the advantage of this format is its direct support for multiple application and services generated by Google and therefore the possibility to combine features and functionality of multiple products into one compact unit. The benefit of applying methods of the thematic mapping it is also a clear visual interpretation of these maps by the general public. Thechance to become familiar with the results of the geographicresearch in very interesting and attractive user-friendly form. [8].

A case study on the GIS in tourism management in China it was found that the roles of GIS in tourism management are mainly in the areas conducting tourism information management and enable to produce a comprehensive thematic map. The existing problems of GIS applications in tourism management at take a panoramic view of the current technology and management system, the key technology and problems to the development and implementation of the GIS were the construction of tourism geographic information database, the data structure and the data model in the design of Tourism Geographic Information Database System [9]. The social impact of ellora caves on the geographical influence of Aurangabad city. The main objective of the research was to highlight the social development in the study region and promote the social importance of tourism in human life. It was also suggested that MTDC should take steps that would attract foreign tourists towards this place. [10]The Maharashtra Tourism Development Corporation (MTDC) started a project as VISION TOURISM 2020in 2010 for the development of tourism sector in Aurangabad. According to the draft plan the main aim of the project is to produce a world class Visitor experience for the Tourists to Aurangabad district leading to their prolonged stay thus developing the ensure the safety, security and comfort, local economy and community of the visitor without degrading the environmental, cultural and social values at the world populace. [11]

\section{GEOGRAPHIC QUERY WORK FLOW}

The touristic information system including tourist sport, historical sport, gate .road, hotel, museum and at the point of these situation to the instance and for the distance between tourist sport and the center of city or railway station, to the capacity and the number of star of hotels and 
it is collected to the map and local municipality from non graphic data and internet.

A geographic search to perform tourism object needs that a geographic representation. The tourism object coordinates are stored in the database.

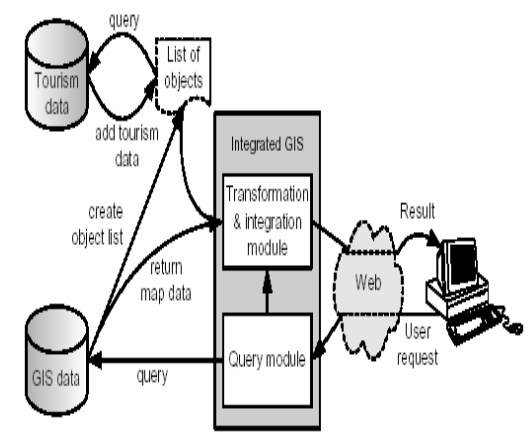

Fig. 1: Geographic Query [12]

This figure shows the workflow of the geographic query which is the transmitted to the user performs a request to the integrated GIS system. In which the queries and spatial database to get on the map data. A Create to the list of tourism object that are located in the area and fulfilling the criteria. Each tourism object completed with data like tourist name, gate name, star hotel, and category of hotel. It is converts the transformation module to the characteristics and the required representation. The module of the integration GIS data with tourism information data, layers and the representation of the tourist object.

\subsection{Integrated GIS}

The benefits of analyzing the GIS integration with the internet, and different two roles in the context of the user. Administration are Position to the object on a map and application are to search for the tourist object .The following above figure show the user of the interaction roles and integrated with the GIS system.

Administration are position to the tourist object that is tourist sport, historical sport, gate, hotel, restaurants sight and event location or other tourist object on a map. The tourism information system integrated with the GIS data and the each location of the tourist object with integrated on to map that has been identified by the geographic coordinate and all user can be identify with the object location an object by selecting the object position on the map. The geographical coordinates an after positioning the object will be calculated by the GIS system and will be stored in the database.An object will be represented on the map creation a symbol, name and category and if the object an tourist place and hotel. The object homepages linked with the object symbol are enabling to further navigation. Application are to search for a tourist object that are the geographic search to perform a functional view and the application uses to a complex geographic queries and to search for the tourist object like are tourist and historical sport, gate, hotel, restaurants, event location .

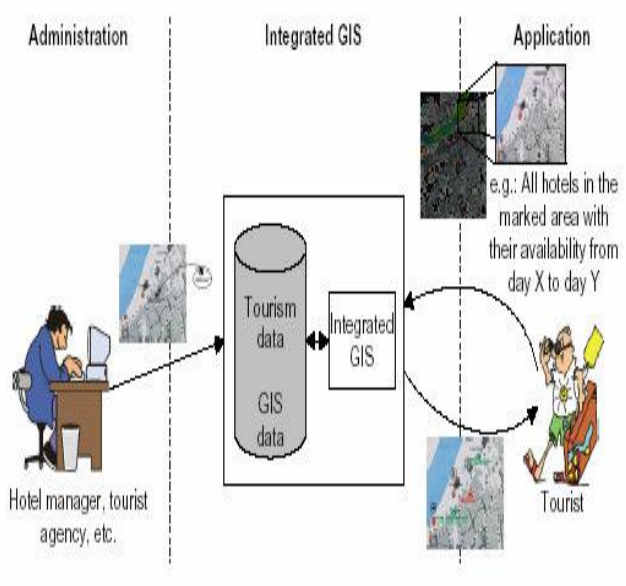

Fig. 2: User of interaction Roles and Integrated with the GIS System. [13]

It is used to thematic map to the tourism information with integrate the GIS data and build tourist maps. A tourist place search can be a time based search and extends to the map and with the detail information availability.

\section{CONCLUSIONS AND FUTURE WORK}

The geo-information product designing and marketing requires which does not start from data collection and method from the user to need at the geo-information product that will be provide useful information and valuable client. The main aim our project to recognize with the tourism information system using Google earth and KML techniques. In described in the paper represents a new approach to the tourism information system on a web is implemented so many people can be share in the data. Feature was the Aurangabad city which will give a preside view for the user in city and thought which we can make decision and can provide a better service level. A tourism application should be equipped the street level data so that the tourist get utmost information to the city and the Google API the specification used by software components to communicate with each other. An API may be described ways in which a particular task is performed. Future work is done for the city and also providing a better view for the users a smarter the information about the city.

\section{ACKNOWLEDGMENTS}

The authors would like to thank the University Authorities for providing the infrastructure to carry out the research. This work is supported by University Grants Commission.

\section{REFERENCES}

[1]. OGC® Approves KML as Open Standard Sam Bacharach Executive Director, "Outreach and Community Adoption Open Geospatial Consortium".

[2]. Ethlers, M.; Jadkowski, M.A.; Howard, R.R.; Brostuen" SPOT data for regional growth analysis and local planning and GIS “, 56,175-180, 1990. 
[3]. David McAdam, "The Value and Scope of Geographical

Information Systems in Tourism Management", International Journal of Science, Research (IJSETR), 1999.

[4]. Duran, Seker, \&Shrestha, "Trip planning and tourist information accessing”, 2004.

[5]. Dr.Virendra R. Nagarale,"Tourist Information System and Their Site Suitability with the Help of GIS Techniques", 2007.

[6]. Prakash J Hajare" The research on the geographical investigation of tourism in Raigad district", July 2012.

[7]. LaveenaT.Dharmani, "Rajasthan Development Tourism", 2005-2010

[8]. VladimírBačík "Creating thematic maps online using PHP, KML and Google Earth, an example of visualizing selected indicators for the Slovak republic".

[9]. Wei Wei," A case study on the GIS in tourism management in China", 2011

[10]. Dr. Madanlal V suryavanshi, "The Social Impact of Ellora Tourism as a Geographical Study", International Research paper, volume3, Issue4, April 2013.

[11]. The Maharashtra Tourism Development Corporation (MTDC) started a project as VISION TOURISM 2020in 2010 for the development of tourism sector in Aurangabad.

[12]. E. Duran, D. Z. seker, M. Shrestha "Web Based Information System for Tourism Resorts".

[13]. E. Duran, D. Z. seker, M. Shrestha "Web Based Information System for Tourism Resorts".

\section{BIOGRAPHIES}

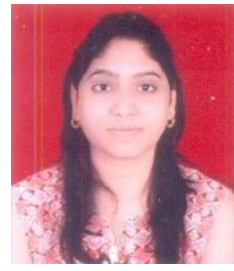

Pallavi U. Pandagale received her Bachelor's Degree in Computer sciences from P. E. S. college of Engineering, Aurangabad.Currently,she is pursuing her Master's in Computer Science \& Engineering from Department of CS \& IT, Dr. Babasaheb AmbedkarMarathwada University, Aurangabad. Her research interest includes GIS and Remote Sensing.

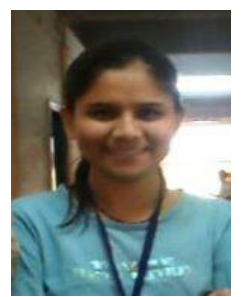

Manisha R.Mundhe received her Bachelor's Degree in Computer sciences from Hi-Tech Institute of Technology, Aurangabad. Currently, she is pursuing her Master's in Computer Science \& Engineering from Department of CS \& IT, Dr. Babasaheb AmbedkarMarathwada University, Aurangabad. Her research interest includes GIS and Remote Sensing.

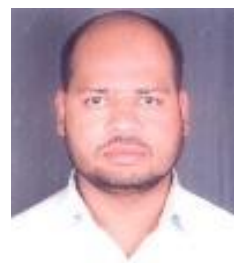

Aminkhan B.Pathanreceived his Bachelor's Degree in Information Technology from Hi-Tech Institute of Technology, Aurangabad. Currently he is pursuing his Master's in Computer Science \& Engineering from Department of CS \& IT, Dr. Babasaheb AmbedkarMarathwada University,Aurangabad. His research interest includes interest includes GIS and Remote Sensing. 